\title{
4. Reflecting regional life: Localness and social capital in Australian country newspapers
}

\section{ABS SIR}

Australian country non-daily newspapers are generally very much local in their emphasis - they cover mostly, or entirely, local news; they promote and advocate for the interests of their region; and they foster a close relationship with their readers. They are not only a valuable source of local news and information for their readership, but also help to connect people within their circulation area and reinforce community identity. This means they are ideally positioned to contribute to social capital - the 'connections among individuals - social networks and the norms of reciprocity and trustworthiness that arise from them' (Putnam, 2000). Social capital can be seen as having three basic components: a network; a cluster of norms, values and expectations; and sanctions that help to maintain the norms and network (Halpern, 2005), and newspapers can contribute to social capital by facilitating local debate and discussion, and reflecting back to communities through the news stories they cover local norms, values, expectations and sanctions. Interrelationships between elements of 'localness' in journalism practice at country newspapers and social capital in regional areas of Australia were explored as part of a wider study of relationships between communities and country newspapers. Journalists, newspaper owners and managers, and community participants from four regions of South Australia and Victoria were asked about their understandings of 'localness' in country newspaper journalism practice. This article suggests that such newspapers' emphasis on localness is a key element of their capacity to contribute to social capital.

Keywords: community newspapers, country newspapers, localness, social capital

\section{KATHRYN BOWD \\ University of South Australia, Adelaide}


7 he term 'social capital' is widely used to refer to 'connections among individuals - social networks and the norms of reciprocity and trustworthiness that arise from them' (Putnam, 2000, p. 19). Social capital has the goal of enhancing quality of life (Schwarz \& Tait, 2007, p. 128) through trust and reciprocity (Winter, 2000, p. 19) and individuals and groups taking an active role (Onyx \& Bullen, 2000, p. 109) to solve collective problems. While it is a contested concept (Winter, 2000, p. 31), and one which defies easy definition, Halpern suggests it has three key component-a network; a cluster of norms, values and expectations; and sanctions that help to maintain the norms and network (Halpern, 2005, p. 10). In the context of a community, the first component is the social network; the second the explicit or implicit rules, values and expectations that characterise the community; and the third ranges from legal punishment to gossip (Halpern, 2005, pp. 10-11).

Theoretical precursors to social capital stretch back to early scholars such as Aristotle (Halpern, 2005, p. 3), but one of the theoreticians most widely associated with the term is Bourdieu, who defines it as 'the sum of the resources, actual or virtual, that accrue to an individual or a group by virtue of possessing a durable network of more or less institutionalised relationships of mutual acquaintances and recognition' (Bourdieu, 1986, p. 248). Bourdieu argues that the volume of social capital possessed by any one person is dependent on the size of the network the person can mobilise and the volume of capital possessed by each person to whom the individual is connected (Bourdieu, 1986, p. 249). He also takes the view that social capital is not independent of other forms of capital, such as economic and cultural capital (Giorgas, 2007, p. 208). Building on Bourdieu's work, Coleman suggests that social capital makes possible 'the achievement of certain ends that would not be attainable in its absence' (Coleman, 1994, p. 302). He argues that social capital is not the private property of any of the persons who benefit from it (Coleman, 1994, p. 315), as 'the actor or actors who generate social capital ordinarily capture only a small part of its benefits' (Coleman, 1988, p. 119).

A third perspective is that of Putnam, who claims that social capital is both a private and a public good, as 'some of the benefit from an investment in social capital goes to bystanders, while some of the benefit redounds to the immediate interest of the person making the investment' (Putnam, 2000, p. 20). He defines social capital as social connections and their attendant norms and 
trusts (Putnam, 1995, p. 665), and suggests that the principle of generalised reciprocity is central: 'I'll do this for you now, without expecting anything immediately in return and perhaps without even knowing you, confident that down the road you or someone else will return the favour' (Putnam, 2000, p. 134). Putnam claims that social capital benefits both individuals and communities by allowing citizens to resolve collective problems more easily; smoothing the way for communities to advance; and widening citizens' awareness of the ways in which their fates are linked (Putnam, 2000, pp. 288-289). The theoretical perspectives of Bourdieu, Coleman and Putnam are in many ways different, but can also be seen as complementary (Woodhouse, 2006, p. 6).

Despite being widely identified as having social benefits, social capital is not an uncontested concept. Putnam suggests that 'bonding' social capital can reinforce exclusive identities (2000, p. 22), while Cox and Caldwell claim it can lead to demonisation of those seen as 'other' (2000, p. 59). Other criticisms of social capital include claims that it promotes individualism and individual gain, that it has been 'hijacked' by the right, and that it has become a tool for neo liberal government reforms (Giorgas, 2007, p. 206). Putnam's and Coleman's theorisations have been criticised for failing to address issues of power and conflict (Giorgas, 2007, p. 211), and it has been suggested that Putnam's conceptualisation is incomplete (Onyx, Edwards \& Bullen, 2007, p. 216). The effects of social capital may also be dependent on context, as Onyx, Edwards and Bullen (2007) suggest: 'Whether or not social capital is used to empower or disempower will depend on the particular intersection of social capital and power relations ...' (p. 229).

In addition, measuring social capital is problematic. Putnam's concern that 'America's stock of social capital has been shrinking for more than a quarter century' (Putnam, 1995, p. 666) is mirrored in Halpern's assessment of social capital in Australia - he claims that, of all countries on which a reasonable range of data is available, Australia shows a pattern most like the US (Halpern, 2005, p. 211). In contrast, however, a 2005 Australian Federal Government report found Australia was relatively well endowed with social capital, with higher rates of volunteering and civic involvement than most developed countries (Bureau of Transport and Regional Economics, 2005, p. v).

Notwithstanding these measurement difficulties, there remains a strong connection in the literature between social capital and non-metropolitan areas, suggesting that social capital is more likely to be found in small towns and rural 
areas than in cities. Although Putnam has expressed concern about declining social capital more generally, he argues that trust and altruism are more likely to be found in small towns (Putnam, 2000, p. 138), and people in rural areas are seen as more likely than others to volunteer, work on community projects, come to the aid of a stranger and donate blood (Beaudoin \& Thorson, 2004, p. 379). Levels of community involvement are high in rural areas and small towns in Australia (Bureau of Transport and Regional Economics, 2005, p. v), and the interrelatedness of social networks in such areas may further reinforce connections: Putnam suggests that the norm of generalised reciprocity is bolstered by 'dense networks of social exchange' (Putnam, 2000, p. 136). The complexities of social capital can be seen in the way different elements of social capital promote differing kinds of connection: 'bonding' social capital promotes and reinforces links between like-minded people; 'bridging' social capital supports the building of connections between heterogeneous groups (Giorgas, 2007, p. 211); and 'linking' social capital brings together 'individuals and groups in different social strata' (Giorgas, 2007, p. 211).

The importance of social capital to regional Australia has become increasingly recognised (de Vrieze, 2006, p. 188; Rogers \& Jones, 2006, p. 9), and there is 'reasonably convincing' evidence that it is associated with positive health, education and life satisfaction and reduced crime and disadvantage (Bureau of Transport and Regional Economics, 2005, p. 213). If social capital helps to hold communities together, institutions that foster its growth may make valuable contributions to life in regional areas. Local news media-including local newspapers - are one such institution.

\section{Localness in newspaper practice}

The benefits of local newspapers for regional areas extend beyond the provision of news and information. Beaudoin and Thorson suggest that:

The news media provide people with opportunities to interact and information that can lead to deliberation and discussion, both of which can encourage civic participation and certain actions that benefit society. In addition, the news media can help hone a community's sense of identity. (2004, p. 381)

Newspapers' contribution to the interaction and social relationships associated with social capital (Hogan \& Owen, 2000, p. 80) may be particularly important at the local level in regional Australia because of increasing 
centralisation of economic power and decision-making (Alston, 2002a, p. 94). Bauman points out that for most people, local issues are the only ones they can actively influence (Bauman, 2007, p. 82), so by facilitating opportunities for people to become involved in such issues, newspapers in country areas play a valuable role in fostering social capital. In her study of relationships between the local press and health and education services in NSW's Riverina district, Blacklow found that as well as providing news and information, newspapers in the area 'served as a forum for expression of the social needs and values which impinged on the daily lives of much of the population' (Blacklow, 2000, p. 226). The ways in which local media facilitate interaction are a key factor in connecting people, empowering communities and building trust and mutuality (Alston, 2002a, pp. 101-102).

Australian country newspapers' contribution to interaction, communication and empowerment in their circulation areas is underpinned by their emphasis on 'localness'. The news focus of such publications - particularly non-daily newspapers - is primarily, or entirely, local; they promote and support the interests and wellbeing of their area, and they are a key part of local communication networks. Although country newspapers are commercial enterprises, with part of the impetus for their establishment that 'businessmen, residents and journalists perceived that their towns had interests separate from other settlements' (Kirkpatrick, 1984, p. 7), they have also 'promoted vigorously the material and social advancement of their town and district' (Kirkpatrick, 1984, p. 7). Changing commercial environments have shifted most newspaper ownership from local to corporate, with the result that 'the family owned and operated provincial newspaper is seldom found' (Kirkpatrick, 2000, p. 225), but most country newspapers remain overwhelmingly local in content. Alysen et al suggest that at their best, 'local papers produce journalism that speaks directly to their audience's concerns' (Alysen et al., 2003, p. 10). They are relatively 'close' to their audiences: 'They [journalists] rub shoulders with their audience and contacts when they're out shopping. They may be involved in the same local organisations. Their children may go to school together' (Alysen et al., 2003, p. 9). They act as community promoters and advocates, often highlighting achievements by local businesses or entrepreneurs. The literature supports the notion of interrelatedness of community integration and newspaper use (Pretty, 1993, p. 81; Park, 1967; Janowitz, 1967; Stamm, 1985), and Ewart claims newspapers 'play a central role in constructing and 
cementing the identity and culture of communities and their publics' (Ewart, 2000). They establish norms for behaviour, appearance and characteristics (Ewart, 2000) and reinforce local identity in the choices they make about what news stories to include, how these are framed and the way language is used.

\section{Methodology}

Interrelationships between elements of 'localness' in journalism practice at country newspapers and social capital were explored as part of a wider study of relationships between communities and country newspapers in regional areas of Australia. Journalists, newspaper owners and managers, and community participants from four regions of South Australia and Victoria were asked about their understandings of 'localness' in country newspaper journalism practice. A case study approach was adopted, with data gathered through semi-structured qualitative interviews and focus groups. Case studies are valuable in putting forward concepts or propositions for further testing or consideration (Punch, 1998, p. 154), and encouraging logical, rather than statistical, inference (Blaikie, 2000, p. 223), even though their potential for generalisability may be limited. In this study, the inclusion of four newspapers representing a range of characteristics typically associated with country newspapers increased the potential for generalisability.

The case study newspapers were chosen as representing a range of characteristics typical of country newspapers. Each is published at least weekly but less frequently than daily; each is a broad-based mainstream publication; and each is published outside a metropolitan area, in a town with a population of less than 15,000 (Australian Bureau of Statistics, 2006). Excluded were newspapers published less frequently than weekly and those published daily; newspapers in metropolitan areas; and specialist publications such as agricultural newspapers. The four newspapers included in the study demonstrate a range of differences: in ownership and management; publication frequency; type of circulation area; and degree of distance from metropolitan areas. Nonetheless, all could be considered typical country newspapers - two locally owned weeklies, a locally owned bi-weekly, and a corporate-owned tri-weekly. While the ownership balance - three locally owned to one corporate-does not reflect broader patterns of country newspaper ownership in Australia, it aimed to maximise the data-gathering potential of the owner/manager interviews because owners were seen as more likely to be in a position to speak openly about issues affecting their publications. 
Within the case study framework, the main data-gathering method employed was semi-structured interviews. Interviews are a frequently utilised method of gathering qualitative data (Fontana \& Frey, 2000, p. 645), and have been widely used in research into journalism (see, for example, Henningham, 1996; Ewart, 1998; Obijiofor, 2001; McGregor, 1993; Molloy \& Bromley, 2009; Manchanda Rodrigues, 2008; Pretty, 1995). Interviewing is a way of 'accessing people's perceptions, meanings, definitions of situations and constructions of reality' (Punch, 1998, pp. 174-175), and semi-structured interviewing maximises flexibility while still providing the opportunity to analyse responses to scheduled questions (Mutchnick \& Berg, 1996, p. 118). The interviews with journalists were conducted face-to-face, and with the managers or owners of each of the four newspapers by phone. Data were gathered from community participants through focus groups, which could be considered to be a form of group interview (Stewart \& Shamdasani, 1990) but allow for efficient data collection from larger numbers of participants.

All of the journalists - including the editors - employed by each of the four newspapers were approached to take part in the study. While all 25 agreed to be involved, two were out of town on the day of the interviews and so were not included. Interviews were also sought with one management representative at each newspaper-in each case the person with the greatest overall responsibility for the publication. One focus group was run in each of the regions covered by the circulation area of the four newspapers, with names of potential participants sourced through the pages of the newspapers, recommendations from newspaper editors, snowball sampling, and lists of upcoming events and their organisers and local institutions and individuals in key areas such as local government. This meant most of the potential focus group participants were individuals who could be seen as community leaders, and helped to ensure they were familiar with the newspaper. Of the 19 to 26 individuals contacted at each location, between four and seven took part in each focus group session. Confidentiality was a key element of the research design, to encourage participants to talk freely and openly. This was seen as particularly important for the journalist participants because of their relationship to the case study newspapers as employees. In reporting the data, confidentiality is maintained through generic identification of participantsfor example, reference to 'experienced bi-weekly journalist' or 'focus group participant' - and random allocation of identifying numbers for individual participants or focus groups. 


\section{Findings}

The responses of participants in this study suggest a strong emphasis on 'localness' by local newspapers. Sub-themes identified included localness of content, local promotion and advocacy, local ownership and sense of ownership, localness of journalists, and relationships with communities. Each of these sub-themes has implications for consideration of interrelationships between newspapers and social capital in regional areas of Australia (for further discussion of these themes, see Bowd, 2010). They can also be seen as supporting the three elements of social capital suggested by Halpernsocial network; rules and expectations; and sanctions. For example, a focus on local content can contribute to social networks by providing a means of linking people in a region, while also providing implicit information about regional norms and sanctions through news choices and framing.

\section{Localness of content}

All three groups of participants-journalists, owners/managers and focus group members-highlighted the local news focus of their local newspaper, and indicated strong support for this. While the degree of localness in news coverage depended in part on the size of the newspaper and whether there were smaller, more localised publications within its circulation area, overall the case study newspapers were seen as very much local in the news stories they covered and the way they covered them. The journalists indicated that local issues and events predominated: '... it's very rare that we do a story outside our geographical area' (J11). Coverage not relevant to the readership could, an editor suggested, be seen as wasting limited editorial space:

... there have been backlashes when we've run non-[local] stuff. The very first thing is while you're putting that in, that space you've just wasted there should be about, you know, the CWA or, or someone local ... (J15)

Broader issues were reported only if they were in some way relevant to the readership or could be localised: ' ... if there's a list of three hundred grants that are made by the federal government in a particular area, we'll always scan the list to see if there's anybody in the [circulation] area, and if there isn't, then we wouldn't run it' (J10). The focus group participants were particularly positive in their views of the localised news coverage provided by the case study 
publications. One Focus Group 4 (FG4) participant suggested that what made the local paper so successful was that it covered only 'stuff that's interesting to local people'. The localness of information such as classified advertising and personal notices in newspapers was also mentioned by focus group participants as a contributor to the reading experience, and as something that helped to make a local newspaper valuable to its readership. Perhaps not surprisingly, the community participants appeared to draw less of a distinction between the news, information and advertising functions of a local newspaper than did the journalist participants.

\section{Local promotion and advocacy}

Along with support for local news coverage, participants expressed support for the idea of country newspapers as local promoters and advocates. But while the broad notion that country newspapers should promote the interests of their region appeared to be widely accepted, the form this promotion and advocacy should take was less clear. Questions about local promotion were framed to participants from the perspective of newspaper campaigning, and responses were varied and diverse across and among participant groups.

Some journalists saw campaigning — which they generally recognised as referring to action by the newspaper ranging from extensive themed coverage of key local issues to suggesting a particular stance or course of action (Bowd, 2007, p. 84) — as an integral part of their newspaper's role, while others believed it should be avoided. One editor took a particularly strong stand, saying campaigning should not be part of a newspaper's role:

... we do have enormous power ... and it should be used in an appropriate way. ... You can still be involved in your community, but actually driving the campaign ... I'm not convinced that is a major role of the newspaper. (J5)

In part, this was because of the difficulty of choosing which issues to support: '.. is getting a new helipad for the hospital any more worthy as a new swimming pool for [a town]?' (J5) However, several other journalists pointed to their newspaper's success in providing a voice for people in their region which, in some cases, had had direct positive outcomes:

... we had some problems with the local ambulance service, and we campaigned and canvassed a few of the problems, and we managed to get the hobnobs to come up here and hold a meeting and everything. (J2) 
The journalists' responses suggested most campaigns were driven by community feeling on an issue, either in direct response to publicly expressed opinion or based on the newspaper's assessment of local sentiment (Bowd, 2007 , p. 85) - 'because we're so close to the community, if the community's campaigning, we're campaigning'. (J18).

Views among the other participant groups also varied widely, with two owner/managers saying campaigning was not part of their newspaper's role, another that his newspaper could or should campaign more, but that responsibility for this rested with the editor, and the fourth that his newspaper campaigned on local issues 'to a degree' (OM1). The focus groups were similarly divided - two indicated their newspaper did not campaign, the third suggested it depended on the issue, and the fourth that the local newspaper had a history of campaigning. However, this disparity of views needs to be seen in the light of broadly expressed support for country newspapers as local promoters and community advocates. It was only the form of the advocacy that generated wide variation in respondent opinion.

\section{Local ownership}

Increased corporate ownership of country newspapers was not seen by participants in this study as inevitably leading to a shift away from community 'ownership' of a publication. Moves away from local ownership were generally identified as less concerning than whether the newspaper was connected with and responsive to its readership, with local content and focus more crucial than who actually owned the publication.

For many of the journalists, the impact of ownership was seen as relatively indirect, affecting budgets and resourcing rather than news content, although some expressed concern that corporate ownership could lead to employment of cheaper, less experienced staff and consolidation of printing facilities, limiting capacity to update editorial content close to deadline (Bowd, 2009, p. 54). The editor of the newspaper owned by a major media organisation argued that who owned the paper was less important than how it was perceived locally:

... I think people aren't really fussed about that [ownership]. ... It's the paper that they see as theirs, not who actually owns it. ... Yes, we're owned by [a major group], but we employ a hundred people who live in the $[$ area] ... (J15)

The views of the newspaper owner/managers were more varied. While 
local ownership was identified as less important than it might once have been (Bowd, 2009, pp. 54-55), concerns were expressed about the effect on local focus of a newspaper being taken over by a large organisation (Bowd, 2009, p. 55). One newspaper owner suggested that: ' $\ldots$ if people saw [a major newspaper group] buy this newspaper and run it the way that they do, they would see a radical difference, I think for the worse.' (OM4)

Most of the community participants indicated that it was preferable-but not essential - that a newspaper be owned within its circulation region. Where concern was expressed about outside ownership, it was at least partly linked to concern about localness of content, with one participant suggesting there was a relationship between 'localness' of a newspaper and the location of its owner, and another that a newspaper should not be run from 'too far afield' (FG3).

Overall, participants were much more positive in responses to questions about sense of community 'ownership'. Almost all of the journalists indicated that readers felt the local newspaper 'belonged' to them (Bowd, 2009, p. 56), with one saying: 'I think they do, very much so. I think that's reflected in letters to the editor and, and regular contributions that we have, complaints that we have ...' (J2) Another junior journalist, at a different newspaper, expressed a similar view: 'It's definitely their paper.' (J16) It was important not to take the relationship for granted, as:

... the worst thing you could possibly do is if someone comes in and starts complaining about 'what are you doing to my paper', if an editor or a general manager says 'well, it's not your paper, it's our paper'. As far as they're concerned, it's their paper-treat it with respect. (J18)

Similar views were expressed by the owner/managers and community participants. Most of the focus group participants indicated that regional residents felt a sense of ownership towards their local newspaper: 'I think we do feel it's our paper, even though we don't own it, I think we do.' (FG3) One FG4 participant suggested it was less a sense of ownership and more a sense of identification with the paper, that it was 'part of the family'. This extended even to people who were not regular readers - one FG2 participant said her husband wouldn't 'actually sit there and read it [the paper], but his friends and he would actually talk about it for days until the next one comes out'. In part, the sense of community ownership reflected the fact many local people were involved in the content of the newspaper, particularly through 
coverage of sport and what were described as 'happy snappies'-photographs of people at community or social events.

\section{Localness of journalists}

Militating against community connection is the high rate of staff turnover at country newspapers. Such publications are widely seen as a 'training ground' for young journalists and university journalism graduates, meaning that many journalists come from outside the newspaper's area, and stay for a relatively short time. This in turn suggests a point of contrast between the intensely local nature of the news coverage and the potentially limited local knowledge of the journalists.

The participants in this study expressed a range of views about the importance of journalists having a local background, but it was generally seen as advantageous, both because of established local connections - 'I've had lots of cases where people have come to me before any other news outlet, with stories ... just because they know who I am, they know the family and me, they trust in that' (J2) - and local knowledge - 'I know a lot of the issues that are facing the [region], having grown up here, having family that live here' (J2). But a more general regional background could provide a broad understanding of regional communities and issues (Bowd, 2005, p. 111-112): '... being born and bred in the country, I think, it makes it easy to relate to a lot of people in the [region], and that's very important.' (J20) Although most community participants saw it as preferable rather than essential that journalists had a background in the region in which they were working, several expressed stronger views: 'They should be local, I reckon. They should know the area. At least lived a couple of years here, not straight from the city.' (FG2)

However, the owner/managers' views were more mixed. One suggested that 'some of our best journalists have just been good year twelve students', and that while journalism graduates had valuable skills, they needed a certain amount of 'retraining' or familiarisation with issues (OM2). At another newspaper, a relatively recent trend towards employing journalists from outside the region had been accompanied by a shift towards less-senior journalists:

When I first started here 15 years ago, our editorial team was, I think a team of about 11 , and they were pretty well all local people and they were all high-graded journalists. We now have a team of 13 and probably only about ... 25 percent of those would be local, but I think the highest grading now, in the journalists, is about a Grade 2. (OM1) 
A third newspaper also employed almost entirely non-local staff, and advertised vacancies in state and interstate metropolitan daily publications. The owner saw this as 'very healthy' because 'outside' journalists brought a fresh perspective (OM4).

One concern raised by participants about the employment of journalists from outside a newspaper's circulation area was that they tended to stay for a relatively short time before moving on to daily newspapers or back to more familiar territory (OM1). The focus groups in particular identified the rate of journalist turnover as problematic, with FG3 participants suggesting journalists needed to make a commitment of at least three years to a region: 'I think most of the reporters we've had over the past five or six years have been there using it as a stepping stone to get further up, that's all it was ...'

This high turnover rate made it difficult for journalists to build up local knowledge, something acknowledged by many participants-particularly those in the focus groups - as problematic. A lack of local knowledge may be particularly obvious to residents who have that knowledge, and can affect perceptions of a journalist's credibility and professionalism: one participant mentioned the example of a journalist new to the region phoning a contact and, in addition to asking the location of a major regional town, mispronouncing the town's name (FG1). The owner/managers also expressed concern about local knowledge: ' ... it probably takes a good young cadet, or young journalist, probably 12 months or more just to get used to the region and to start making good solid contact'. (OM1) Journalists from metropolitan areas were seen as being at a particular disadvantage, with one focus group participant saying a greater investment of time was required when providing information to journalists from the city, as more explanation of issues was necessary.

Participants suggested that lack of local knowledge could be addressed in part by immersion in the region, which helped to develop a sense of 'connection'. Being visible within the area was part of this: 'I guess it's important to have a bit of a face out there in the community, to go to a lot of local events so people know who you are.' (J19) But it was nonetheless highlighted as problematic given the predominantly local nature of the news covered.

\section{Relationships with communities}

Maintaining a close relationship between newspaper and audience may be a way of consolidating newspapers' place in local communication networks, 
and one element of this is communication between publication and readership. Journalists at country newspapers are usually readily accessible to their audiences, something described by one tri-weekly journalist as building integrity into the process of communicating the news (J22). He saw this as important because sloppy or inaccurate reporting would undermine the paper's reputation, which would in turn lessen readers' regard for it. The ease of contact was viewed by community members as a 'bit of a privilege' (FG1): 'I think most of us appreciate the fact that we can actually go and do that ... [talk to a journalist].' (FG2) For journalists, being known within the region helped to balance the information-gathering limitations of small numbers of journalists covering large geographical areas: '... we do rely a hell of a lot on people coming in and letting us know, because obviously with resources you can't get out and know what's going on everywhere.' (J8)

The nature of the relationship between newspaper and audience is also reflected in what many participants identified as country newspapers' concern with the consequences of their reporting. For example, the reporting of tragic events such as fatal car accidents is something that would be approached cautiously:

... we'd look at each one as an individual case. We certainly wouldn't publish a picture with a body in it, and we certainly wouldn't publish a picture which is a candid or impromptu picture showing an accident victim, and they weren't aware that a picture was being taken. (OM4)

As one of the journalists suggested:

... it's not the same as working in a major national or state paper, where you can meet someone and can write anything from that, and you don't have to worry so much about the consequences. I mean, we live with these people, and we have to work with these people ... (J2)

Focus group participants identified this as something that distinguished local papers from metropolitan publications:

In national papers they've got to, I think, to strive for sensation ... Whereas, being a community based [paper], they've also got to live here, and I think that makes a big difference. 


\section{Conclusion}

Localness is noted in the literature as an identifying characteristic of country newspapers in Australia (Kirkpatrick, 2001; Pretty, 1993; 1995), and the responses of participants in this study support this idea and suggest that localness is viewed positively by news audiences. Localness is at the centre of country newspapers' mission, which one weekly journalist described as:

answering the questions that the community has, finding out the information that the community wants to know, and just holding up all those basic principles of journalism, you know, informing people, educating people and that sort of stuff as well. (J3)

Local newspapers afforded a venue for community discussion and a means by which people could communicate with each other, as well as a 'sounding board' to let people know:

how their community is ticking, how the health of the community-is it dealing with issues, like for example, water issues, the drought, markets, overseas competition for imports and things like that on fruit and other things-how we measure up. (OM2)

They also helped to establish regional identity:

I just think kind of it's a nice sense of community, that you sort of, everyone from all across the [region] are reading it and can find out what's happening in the [region], get a sense of community and belonging. It's a nice way of separating the [region] from [nearby areas] ... (FG4)

A newspaper that is 'connected' to its audience helps to connect people within that readership. As Kirkpatrick suggests: 'In many instances, the community newspaper is communicating the good news that nothing terrible has happened in the past week ...' (Kirkpatrick, 2001, p. 20)-but even these types of messages are valuable in maintaining community links.

The responses of participants in this study indicate that country newspapers are a crucial element of local communication networks, although shifting patterns of media engagement - and particularly generational change- have the capacity to affect the place of newspapers in these networks. Country newspapers' central role as a community connector suggests they are well positioned to contribute to social capital in their circulation regions. In reporting on a 
wide range of events and activities within their readership areas, they circulate information about achievements, events and other elements of regional life. This is further reinforced by the multi-layered nature of connections in small towns, where the people involved in local sport are often the same people involved in service club meetings and whose other achievements might also be reported in the pages of the paper, reflecting the 'dense networks of social exchange' that Putnam suggests bolster the norm of generalised reciprocity (Putnam, 2000, p. 136).

Country newspapers support the components of social capital identified by Halpern-a network; norms, values and expectations; and sanctions (Halpern, 2005, p. 10) - by identifying what they believe is important to their readership, through their focus on local content and interests, and reflecting this back to readers. Both formal and informal norms and sanctions (Halpern, 2005, p. 12) are supported through news coverage, particularly through reporting of community responses to issues and events. Ewart suggests regional media play a central role in constructing and cementing the identity and culture of communities and their publics, and that a community comes to recognise and know itself through its representation in local media (Ewart, 2000).

Participants' responses also indicate that this may work less effectively where localness is seen as lacking - in particular as a result of rapid turnover and limited local knowledge of journalists. Lack of local understanding may militate against journalists reporting in more than a superficial manner, as they may be unaware of underlying issues, conflicts and personalities, as well as the unwritten 'rules' and norms of a region. Rapid turnover of journalists thus may impact on public perceptions of a newspaper, with consequent limitations on its ability to contribute to social capital.

The sub-themes identified above demonstrate ways in which country newspapers can contribute to social capital in their circulation region. By concentrating on local news and the interests of their region, they help to develop and maintain links between people in the region. By emphasising 'localness', they reinforce what it is that people in the region have in common, what characterises local identity, the norms and expectations that are part of regional life, and the concerns and interests of people in their circulation area. Regional newspapers may also help to bridge divides between sub-communities in regional areas by effectively promoting characteristics of 'bridging' social capital. While a detailed exploration of sub-communities is 
beyond the scope of this article, the broad themes emerging from the research support the idea of country newspapers as a generally uniting force within regional communities.

Coleman argues that social capital depreciates if not renewed, as 'social relationships die out if not maintained; expectations and obligations wither over time; and norms depend on regular communication' (Coleman, 1994, p. 321). Country newspapers can help to maintain relationships, expectations and norms by reflecting back to communities messages about what is considered important to people in their region, and by presenting the views and opinions of local people, celebrating their achievements and focusing on local people and issues. In this way, they can make a valuable contribution to the ongoing renewal of social capital in their area.

\section{References}

Alston, M. (2002a). Social capital in rural Australia. Rural Society, 12(2), pp. 93-104. Alston, M. (2002b). From local to global: Making social policy more effective for rural community capacity building. Australian Social Work, 55(3), pp. 214-226.

Alysen, B., Sedorkin, G., et al. (2003). Reporting in a multimedia world. Crows Nest, NSW, Allen \& Unwin.

Australian Bureau of Statistics. (2006). 2006 census quickstats by location. Retrieved on 15 April 2010, from www.censusdata.abs.gov.au/ABSNavigation/prenav/Pro ductSelect?newproducttype $=$ QuickStats\&btnSelectProduct $=$ Select + Location $+\%$ $3 E \&$ collection $=$ Census $\&$ period $=2006 \&$ areacode $=\&$ geography $=\&$ method $=\&$ pro ductlabel $=\&$ producttype $=\&$ topic $=\&$ navmapdisplayed $=$ true $\&$ javascript $=$ true $\& b r$ eadcrumb $=$ P\&topholder $=0 \&$ leftholder $=0 \&$ currentaction $=201 \&$ action $=104 \&$ tex tversion $=$ false.

Bauman, Z. (2007). Liquid times: Living in an age of uncertainty. Cambridge, Polity.

Beaudoin, C. E. \& Thorson, E. (2004). Social capital in rural and urban communities:

Testing differences in media effects and models. Journalism and Mass Communication Quarterly, 81(2), pp. 378-399.

Blacklow, N. (2000). In the interests of rural society: The Riverina press and the provision of health and education. Rural Society, 10(2), pp. 215-228.

Blaikie, N. (2000). Designing social research. Cambridge, Polity Press.

Bourdieu, P. (1986). The forms of capital. In J. Richardson (Ed.)., Handbook of theory and research for the sociology of education (pp. 241-258).New York, Greenwood Press.

Bowd, K. (2005). Country newspaper journalists' perceptions of the influence of 'localness' on professional practice. Australian Journalism Review, 27(2), pp. 105-117.

Bowd, K. (2007). A voice for the community: Local newspaper as local campaigner. Australian Journalism Review, 29(2), pp. 77-89. 
Bowd, K. (2009). 'Did you see that in the paper?': Country newspapers and perceptions of local 'ownership'. Australian Journalism Review, 31(1), pp. 49-61.

Bowd, K. (2010). Local voice, local choice: Australian country newspapers and notions of community. Unpublished $\mathrm{PhD}$ thesis, University of South Australia.

Bureau of Transport and Regional Economics (2005). Focus on regions No. 4 social capital. Canberra, Department of Transport and Regional Services.

Coleman, J. (1994). Foundations of social theory. Cambridge, Massachusetts, Belknap Press.

Coleman, J.S. (1988). Social Capital in the Creation of Human Capital. The American Journal of Sociology 94(Supplement: Organisations and institutions-sociological and economic approaches to the analysis of social structure): S95-S120.

Cox, E. \& Caldwell, P. (2000). Making policy social. In I. Winter (Ed.,)., Social capital and public policy in Australia (pp. ?????). Melbourne: Australian Institute of Family Studies.

de Vrieze, D. (2006). The business network as community engagement. In M. Rogers and D. Jones The changing nature of Australia's country towns (pp. 188195). Ballarat, VURRN Press.

Ewart, J. (1998). What a difference two weeks makes: The importance of training in the acceptance of pagination. Australian Journalism Review 20(1), pp. 23-37.

Ewart, J. (2000). Capturing the heart of the region: How regional media define a community. Transformations(1).

Ewart, J. \& Massey, B.L. (2005). 'Local (people) mean the world to us': Australia's regional newspapers and the 'closer to readers' assumption'. Media International Australia(115):, pp. 94-108.

Ewart, J., Meadows, M., et al. (2005). Media matters: Ways to link community radio and community newspapers. Australian Journalism Review. 27(2), pp. 87-103.

Fontana, A. \& Frey, J.H. (2000). The interview: From structured questions to negotiated text. In N. K. Denzin and Y. S. Lincoln (Eds.)., Handbook of qualitative research (pp. 645-672). Thousand Oaks, California, Sage.

Giorgas, D. (2007). The significance of social capital for rural and regional communities. Rural Society 17(3), pp. 206-214.

Halpern, D. (2005). Social capital. Cambridge, Polity Press.

Henningham, J. (1996). Journalists' perceptions of newspaper quality. Australian Journalism Review 18(1), pp. 13-19.

Hogan, D. \& Owen, D. (2000). Social capital, active citizenship and political equality in Australia. In I. Winter, Social capital and public policy in Australia. Melbourne, Australian Institute of Family Studies.

Ife, J. (2002). Community development: Community-based alternatives in an age of globalisation. Frenchs Forest, NSW, Pearson Education Australia.

Janowitz, M. (1967). The community press in an urban setting. Chicago, University of Chicago Press.

Kirkpatrick, R. (1984). Sworn to no master. Toowoomba, Darling Downs Institute Press. 
Kirkpatrick, R. (2000). Country conscience: A history of the New South Wales provincial press, 1841-1995. Canberra, Infinite Harvest Publishing.

Kirkpatrick, R. (2001). Are community newspapers really different? Asia Pacific Media Educator(10), pp. 16-21.

Manchanda Rodrigues, U. (2008). Changing newsrooms: A survey of journalists in Victoria, Australia. Australian Journalism Review 30(1), pp. 113-122.

McGregor, J. (1993). A survey of Maori journalists. Australian Journalism Review 15(2), pp. 17-22.

Molloy, S. \& Bromley, M. (2009). Stirred but not shaken: How the next generation is adapting to the online domain. Australian Journalism Review 31(1), pp. 77-90.

Mutchnick, R. J. \& Berg, B.L. (1996). Research methods for the social sciences: Practice and applications. Needham Heights, Massachusetts, Allyn \& Bacon.

Obijiofor, L. (2001). Singaporean and Nigerian journalists' perceptions of new technologies. Australian Journalism Review 23(1), pp. 131-151.

Onyx, J., Edwards, M. \& Bullen, P. (2007). The intersection of social capital and power: An application to rural communities. Rural Society 17(3), pp. 215-230.

Park, R.E., Burgess, E.W., et al. (1967). The city. Chicago, University of Chicago Press.

Pretty, K. (1993). Dusting off the grassroots: A survey of Australian country journalists. Australian Studies in Journalism(2), pp. 75-123.

Pretty, K. (1995). Rural newspaper journalists: Who are they? In P. Share (Ed.)., Communication and Culture in Rural Areas (pp. 199-217). Wagga Wagga, Centre for Rural Social Research.

Punch, K. F. (1998). Introduction to social research: Quantitative and qualitative approaches. London, Sage.

Putnam, R.D. (1995). Tuning in, turning out: The strange disappearance of social capital in America. PS: Political Science and Politics, 28(4), pp. 664-683.

Putnam, R.D. (2000). Bowling alone: The collapse and revival of American community. New York, Simon \& Schuster.

Rogers, M. \& Jones, D. (2006). Introduction—renewing country towns. In M. Rogers and D. R. Jones (Eds.)., The changing nature of Australia's country towns (pp. 7-13). Ballarat, VURRN Press.

Schwarz, E.C. \& Tait, R. (2007). Recreation, arts, events and festivals: Their contribution to a sense of community in the Colac-Otway shire of country Victoria. Rural Society 17(2), pp. 125-138.

Stamm, K.R. (1985). Newspaper use and community ties: Toward a dynamic theory. Norwood, New Jersey, Ablex.

Stewart, D.W. \& Shamdasani, P.N. (1990). Focus groups: Theory and practice. Newbury Park, California, Sage.

Winter, I. (2000). Social capital and public policy in Australia. Melbourne, Australian Institute of Family Studies.

Woodhouse, A. (2006). 'People are accepted as long as they don't misbehave': Exploring the relationship between social capital and crime in rural Australia. Rural Society 16(1), pp. 5-24. 
Dr Kathryn Bowd is program director of undergraduate journalism at the University of South Australia, Adelaide. An earlier version of this article waspresented at the Journalism Education Association of Australia (JEAA) annual conference at the University of Technology, Sydney, in November 2010. Kathryn.Bowd@unisa.edu.au

\section{ADT COMMUNICATIONS}

\section{POSTGRADUATEJOURNALISM}

Bachelor of Communication Studies(Hons) offers students either anapplied or an academic pathway incommunication studies. Papers and strands include Asia-Pacific journalism, digital media, investigative journalism, public relations and screen writing.

Master of CommunicationsStudies(MCS) is a postgraduateresearch degree offering practical options. Doctorate in Communication Studies (PhD) is a thesis-based research degreegranted on the basis of $x$ original and substantive contribution toknowledge. The Faculty of Designand ereative lndustries encourages and supports innovative interdisciplinary research. The School of Communication Studies has supervising staff whose research interests cover a range of areasencompassing media, politics and ownership, journalism, human communication, new media and development, discourse analysis and popular culture.

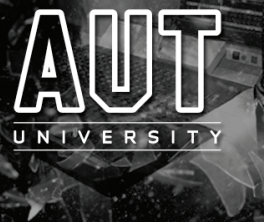

